\title{
Het gebruik van bepaalde en onbepaalde lidwoorden in het Nederlands door Tsjechische studenten Nederlands
}

\begin{abstract}
In their studies (2003, 2004 and 2008) Ionin et al. examined English article use by L2-English speakers. They found that speakers of an article-less L1 (Korean and Russian) make mistakes mainly in two of the total four conditions of English article use. By contrast, speakers whose L1 has articles (Spanish) do not show any particular pattern of article misuse. In this study Ionin et al.'s methodology was used to investigate article use in Dutch by Czech students of Dutch. It was found that Czech learners of Dutch fluctuate between definiteness and specificity in their article use because they overuse the indefinite article in [+def, -spec] condition and they overuse the definite article in [-def, + spec] condition. By analysing data of particular proficiency groups, it was found that article use by Czech learners of Dutch tends to improve as their proficiency increases.
\end{abstract}

\section{Inleiding}

Bijna iedereen die Nederlands leert kent het eeuwige probleem en stelt zich vaak de vraag "Is dit een de- of het-woord?" Niet alleen het gebruik van de twee verschillende bepaalde lidwoorden maakt het aanleren van de Nederlandse lidwoorden moeilijk, ook het onderscheid tussen bepaalde en onbepaalde lidwoorden is een lastig probleem voor veel studenten Nederlands.

In dit artikel wordt een onderzoek naar het gebruik van bepaalde en onbepaalde lidwoorden in het Nederlands door Tsjechische studenten Nederlands beschreven. Dit onderzoek heb ik (toenmalige studente Nederlands aan de Universiteit Palacký te Olomouc) in samenwerking met de Tsjechische studente Nederlands Lucie Gajdošová (Karlsuniversiteit te Praag) in 2013 aan de Universiteit van Amsterdam verricht. Het gebruik van bepaalde en onbepaalde lidwoorden is eerder door Tania Ionin et. al (2003, 2004 en 2008) onderzocht. In hun onderzoek hebben ze zich op het lidwoordengebruik van Russische sprekers Engels gericht. Ze 
hebben gevonden dat Russische sprekers fouten maken vooral in twee condities, namelijk in [+def, -spec] en [-def, + spec] condities. De methodologie van haar onderzoek is ook in dit onderzoek toegepast om te achterhalen of ook Tsjechische sprekers Nederlands de meeste fouten in deze twee condities maken.

Eerst zal de theoretische achtergrond van dit onderzoek besproken worden, waaruit de hypothesen en voorspellingen voortvloeien. Vervolgens komt de methode aan bod waarin deelnemers, materiaal, procedure en analyse van dit onderzoek behandeld worden. Na de bespreking van de resultaten volgt de discussie waarin de resultaten verklaard worden. Tot slot volgt de conclusie van dit onderzoek.

\section{Theoretische achtergrond}

\subsection{Het gebruik van lidwoorden in het Nederlands}

In het Nederlands worden twee bepaalde lidwoorden, namelijk de en het en een onbepaald lidwoord, namelijk een gebruikt. Om de Nederlandse lidwoorden correct te kunnen gebruiken, moet de spreker naast het geslacht ook de juiste semantisch-pragmatische categorie van het zelfstandig naamwoord kennen, namelijk of het bepaald en/of specifiek is. In de onderstaande alinea's worden deze twee semantisch-pragmatische categorieën toegelicht.

\section{Bepaaldheid}

Bepaaldheid van een zelfstandig naamwoord is gebaseerd op het gesprek. Een bepaald lidwoord (de of het) wordt gebruikt als in een bepaalde context het zelfstandig naamwoord zowel bij de spreker als de toehoorder bekend is (Schaeffer et al, 2005) zoals geïllustreerd in de tweede zin in (1). In het geval dat een zelfstandig naamwoord minimaal bij de toehoorder onbekend is, wordt een onbepaald lidwoord (een) gebruikt, zoals aangetoond in de eerste zin in (1).

(1) Ik heb gisteren een boek en twee tijdschriften gekocht. Het boek gaat over de geschiedenis van Frankrijk.

In de tweede zin in (1) is het bepaalde lidwoord het gebruikt omdat men weet dat het boek gisteren gekocht is en het boek daarom al bekend is. In de eerste zin in (1) wordt daarentegen het onbepaalde lidwoord een gebruikt omdat het boek nog onbekend is en pas geïntroduceerd wordt.

\section{Specificiteit}

Net zoals de bepaaldheid is de specificiteit van een zelfstandig naamwoord gebaseerd op het gesprek. Als de spreker naar een bepaald afzonderlijk zelfstan- 
dig naamwoord verwijst dat een opmerkelijke eigenschap heeft, is dit zelfstandig naamwoord specifiek (Schaeffer et al, 2005). Dit wordt geïllustreerd in (2).

(2) $[+$ bep, + spec $]$

Louise: Waar is je moeder?

Julie: $\quad$ Ze is bij de directeur van de basisschool van mijn broer. Hij is heel aardig. Ze praten over de cijfers van mijn broer.

Er is maar een directeur van de basisschool en bovendien is het bekend dat hij een aardige man is. In tegenstelling tot dit voorbeeld wordt in (3) een non-specifiek zelfstandig naamwoord aangeduid.

(3) [+bep, -spec]

In een speelgoedwinkel

Verkoper: Kan ik u helpen?

Klant: Ja, ik ben echt boos. Ik heb speelgoed voor mijn kind in deze winkel gekocht maar het is kapotgegaan! Ik wil met de eigenaar van deze winkel spreken. Het maakt niet uit wie dat is. Ik wil een klacht indienen!

Hoewel de speelgoedwinkel maar een eigenaar heeft, is hij of zij voor de spreker niet bekend, slechts voor de toehoorder.

In tegenstelling tot bepaaldheid, die door het gebruik van een bepaald of onbepaald lidwoord duidelijk is, is specificiteit morfosyntactisch ongemarkeerd. Hoewel in (2) en (3) beide zelfstandige naamwoorden het bepaald lidwoord de hebben, is het zelfstandig naamwoord in (2) specifiek terwijl het zelfstandig naamwoord in (3) non-specifiek is.

\section{Bepaaldheid en specificiteit}

Voorbeeldzinnen (2) en (3) illustreren zelfstandige naamwoorden die resp. bepaald en specifiek (2) en die bepaald en tegelijkertijd non-specifiek zijn (3). Maar ook de volgende twee combinaties zijn mogelijk. Een zelfstandig naamwoord kan onbepaald en tegelijkertijd specifiek zijn (4) als ook onbepaald en tegelijkertijd non-specifiek (5).

(4) [-bep, + spec]

Opa op bezoek

Opa: Waar is mijn lieve kleindochtertje Marjolein? Is ze thuis?

Vader: Nee, ze komt pas later thuis. Ze is op bezoek bij een klasgenote. Ze heet Tinka en Marjolein houdt erg veel van haar.

(5) [-bep, -spec]

Rosa: Wil je dit weekend met me shoppen? 
Ingrid: Ja, zeker. Naar welke winkel wil je gaan?

Rosa: Dat maakt niet uit. Ik ben op zoek naar een warme muts. Het is zo koud buiten!

Voorbeeldzinnen (2), (3), (4) en (5) laten dus zien dat alle combinaties van (on)bepaaldheid en (non-)specificiteit mogelijk zijn. Dit is samengevat in tabel (1).

Tabel (1) Lidwoordengebruik in vier verschillende condities

\begin{tabular}{|c|c|c|}
\hline & +bep & -bep \\
\hline + spec & \multirow{2}{*}{ de/ het } & een \\
\cline { 1 - 1 } - spec & & \\
\hline
\end{tabular}

\subsection{Tsjechisch}

Het Tsjechisch is een Slavische taal die geen lidwoorden heeft. Zowel bepaaldheid als specificiteit is voor de sprekers duidelijk uit de gespreksituatie. Een [+bep, + spec] zelfstandig naamwoord kan (maar hoeft niet ${ }^{1}$ ) met behulp van een aanwijzend voornaamwoord uitgedrukt worden als in (6).

(6) Víš, že ta holka, o které jsem včera mluvil, pochází z Německa? Weet je dat dat meisje, waar ik gisteren over sprak, uit Duitsland komt?

Ook een [-bep, -spec] zelfstandig naamwoord kan (maar hoeft niet ${ }^{2}$ ) door een onbepaald voornaamwoord worden ingeleid. Dit is aangetoond in (7).

(7) Petra: Půjdeš se mnou o tomto víkendu nakupovat?

Karin: Jasně. Kam chceš zajít?

Petra: Kamkoliv. Potřebuji nějakou teplou čepici. Venku už začíná být zima.

Petra: Wil je dit weekend met me shoppen?

Karin: Ja, zeker. Naar welke winkel wil je gaan?

Petra: Dat maakt niet uit. Ik ben op zoek naar de ene of de andere warme muts. Het is zo koud buiten!

\footnotetext{
${ }^{1}$ Zelfstandig naamword hoeft niet door een voornaamwoord ingeleid te worden.

2 Ditto.
} 


\subsection{Eerder onderzoek}

In 2003 en 2004 hebben Ionin et al. de verwerving van lidwoorden in het Engels door volwassen moedertaalsprekers Russisch en Koreaans onderzocht. Een van hun bevindingen was dat deelnemers aan hun onderzoek geen random fouten maakten, maar dat hun fouten in twee soorten waren in te delen. Ten eerste gebruikten ze het onbepaalde lidwoord een overmatig in de [+bep, -spec] conditie, en ten tweede gebruikten ze het bepaalde lidwoord de/het overmatig in de [-bep, +spec] conditie. In de twee overige condities, dus in [+bep, +spec] en [-bep, -spec], gebruikten ze de lidwoorden meestal op de juiste manier. Ionin et al. Hebben geconcludeerd dat dit specifieke gebruik van lidwoorden door de schommeling tussen de bepaaldheid en de specificiteit van moedertaalsprekers Russisch en Koreaans veroorzaakt is. Noch in het Russisch noch in het Koreaans (noch in het Tsjechisch) zijn bepaaldheid en specificiteit gemarkeerd door lidwoorden omdat geen van deze talen lidwoorden heeft. Taalgebruikers die niet weten dat het lidwoordengebruik in het Engels, net zoals in het Nederlands, op de bepaaldheid gebaseerd is, weten niet of ze het betreffende lidwoord volgens bepaaldheid of specificiteit moeten bepalen. Daarom schommelen ze tussen deze twee categorieën. De schommeling komt slechts in twee condities aan het licht, namelijk in de [+bep, -spec] en [-bep, + spec] condities, waar ze de meeste fouten maken. In de twee overige condities, in [+bep, +spec] en [-bep, -spec] is hun lidwoordgebruik redelijk accuraat omdat deze beide categorieën tot het gebruik van het bepaalde lidwoord de of het, of van het onbepaalde lidwoord een leiden.

In hun onderzoek uit 2008 naar het lidwoordgebruik in het Engels door moedertaalsprekers Russisch en Spaans vonden Ionin et. al hetzelfde kenmerkende lidwoordengebruik door Russisch sprekers opnieuw. Russische sprekers maken vooral fouten in [+bep, -spec] en [-bep, + spec] condities. In tegenstelling tot de Spaanse sprekers, die een relatief accuraat lidwoordengebruik tonen. Het Spaans heeft namelijk lidwoorden die net zoals in het Engels en Nederlands op de bepaaldheid gebaseerd zijn. Daarom maakten Spaanse deelnemers weinig fouten met Engelse lidwoorden. De resultaten van dit onderzoek zijn weergegeven in tabel (2).

Tabel (2) Het succespercentage van deelnemers uit Ionin et al. uit 2008

\begin{tabular}{|l|c|c|c|c|}
\hline & [+bep, +spec] & [+bep, -spec] & [-bep, +spec] & [-bep, -spec] \\
\hline $\begin{array}{l}\text { moedertaalsprek- } \\
\text { ers Engels }^{1} \text { (n= 6) }\end{array}$ & 100 & 100 & 94,4 & 100 \\
\hline $\begin{array}{l}\text { moedertaalsprek- } \\
\text { ers Spaans (n= 20) }\end{array}$ & $87,5^{2}$ & 96,7 & 92,5 & 91,7 \\
\hline $\begin{array}{l}\text { moedertaalsprekers } \\
\text { Russisch (n= 19) }\end{array}$ & 93 & 86 & 74,6 & 95,6 \\
\hline
\end{tabular}


Ionin et al. hebben eerder geconcludeerd dat het lidwoordgebruik in het Engels door Russische sprekers zich verbetert naarmate hun taalvaardigheid groeit.

\section{Hypothesen een voorspellingen}

Aangezien het Tsjechisch net als het Russisch geen lidwoorden heeft en het lidwoordgebruik in het Nederlands net als in het Engels op de bepaaldheid gebaseerd is, kon onderzocht worden of ook Tsjechische sprekers Nederlands vooral fouten maken in de [+bep, -spec] en [-bep, + spec] condities. Naar aanleiding van de behandelde literatuur was de verwachting dat Tsjechische sprekers Nederlands tussen bepaaldheid en specificiteit in het Nederlandse lidwoordgebruik zouden schommelen (hypothese 1). Verder veronderstelden we dat de schommeling tussen bepaaldheid en specificiteit in het Nederlandse lidwoordgebruik zou afnemen naarmate de taalvaardigheid zou groeien (hypothese 2).

Hypothese 1 zou bevestigd worden als de Tsjechische sprekers Nederlands het onbepaalde lidwoord een in [+bep, -spec] overmatig zouden gebruiken en in [-bep, + spec] het bepaalde lidwoord de of het. Dit is geillustreerd in respectievelijk (8) en (9).

(8) [+bep, -spec]

In de speelgoedwinkel

Verkoper: Kan ik u helpen?

Klant: Ja, ik ben echt boos. Ik heb speelgoed voor mijn kind in deze winkel gekocht maar het is kapot gegaan! Ik wil met een* (de geëist) eigenaar van deze winkel spreken. Het maakt niet uit wie dat is. Ik wil een klacht indienen!

(9) [-bep, +spec]

Opa op bezoek

Opa: Waar is mijn lieve kleindochtertje Marjolein? Is ze thuis?

Vader: Nee, ze komt pas later thuis. Ze is op bezoek bij de (een geëist) klasgenote. Ze heet Tinka en Marjolein houdt erg veel van haar.

Als Tsjechische sprekers Nederlands daarentegen geen fouten in het lidwoordgebruik zouden maken of hun fouten zouden willekeurig zijn, zou dit hypothese 1 weerleggen.

Hypothese 2 zou bevestigd worden als Tsjechische sprekers met een lager taalvaardigheidsniveau in het Nederlands meer tussen bepaaldheid en specificiteit zouden schommelen dan Tsjechische sprekers Nederlands met een hoger taalvaardigheidsniveau in het Nederlands. Dat zou dus betekenen dat ze steeds minder fouten in de [+bep, -spec] en [-bep, + spec] condities zouden maken naarmate hun taalvaardigheidsniveau in het Nederlands zou verbeteren. 
Als Tsjechische sprekers Nederlands met verschillende taalvaardigheidsniveaus echter hetzelfde succespercentage zouden vertonen of sprekers met een lager taalvaardigsheidniveau minder fouten zouden maken dan gevorderde sprekers, zou dit hypothese 2 weerleggen.

\section{Methode}

\subsection{Deelnemers}

De deelnemers aan dit onderzoek waren bachelor en master studenten Nederlands aan de Tsjechische universiteiten in Brno, Olomouc en Praag. Al drie vakgroepen gebruiken verschillende leerboeken waarin nadruk op grammatica in meerdere (Brno, Praag) of mindere (Olomouc) mate is gelegd. Aangezien eerstejaarsstudenten in de tijd van het testen (november 2013) nog een heel laag taalvaardigheidsniveau in het Nederlands hadden, werden studenten pas vanaf het tweede studiejaar getest. Er werden ook oud studenten onderzocht die hun opleiding in 2013 hebben afgerond.

In totaal hebben 78 studenten aan het onderzoek deelgenomen. Drie studenten moesten uiteindelijk van het onderzoek worden uitgesloten, omdat twee van hen tweetalig waren en bij een van hen hun taalvaardigheidsniveau onbekend was (niet ingevuld door de student). De geteste studenten hadden minimaal een jaar en twee maanden en maximaal zes jaar en twee maanden studie Nederlands achter de rug. De deelnemers waren tussen de 20 en 27 jaar oud. Studenten werden op basis van hun behaalde Certificaat Nederlands als Tweede Taal (CNaVT) in vier taalvaardigheidsgroepen (van A2 tot C1) verdeeld. Studenten die geen certificaten hadden maar wel hun bachelor titel hadden gehaald, werden in de niveaugroep B2 gerangschikt. Tabel (3) geeft informatie over de leeftijd en leertijd van studenten en tabel (4) toont hun verdeling per taalniveau en universiteit aan.

Tabel (3) De achtergrond van deelnemers

\begin{tabular}{|c|c|c|c|}
\hline Groep & $\begin{array}{c}\text { Aantal deel- } \\
\text { nemers }\end{array}$ & Leeftijd & Leertijd \\
\hline A2 & 20 & $20-25$ & $1 \mathrm{j} 2 \mathrm{~m}-1 \mathrm{j} 3 \mathrm{~m}$ \\
\hline B1 & 21 & $20-25$ & $2 \mathrm{j} 3 \mathrm{~m}-4 \mathrm{j} 4 \mathrm{~m}$ \\
\hline B2 & 22 & $22-26$ & $3 \mathrm{j} 3 \mathrm{~m}-4 \mathrm{j} 8 \mathrm{~m}$ \\
\hline C1 & 12 & $23-27$ & $4 \mathrm{j} 3 \mathrm{~m}-6 \mathrm{j} 2 \mathrm{~m}$ \\
\hline
\end{tabular}


Tabel (4) Het aantal deelnemers per universiteit en taalvaardigheidsniveau

\begin{tabular}{|c|c|c|c|}
\hline & Brno & Olomouc & Praag \\
\hline A2 & 0 & 12 & 8 \\
\hline B1 & 10 & 8 & 3 \\
\hline B2 & 3 & 15 & 4 \\
\hline C1 & 0 & 6 & 6 \\
\hline
\end{tabular}

Sommige studenten waren moedertaalsprekers Slowaaks. Aangezien Slowaaks net als Tsjechisch (en Russisch) geen lidwoorden heeft, mochten deze studenten aan het onderzoek ook deelnemen.

Alle geteste studenten hadden taalvaardigheidsniveau B2 in het Engels of het Duits (zelf aangegeven in een formulier). Dat betekent dat geen van de geteste studenten profijt kon trekken van zijn kennis van lidwoordengebruik in een andere taal ten opzichte van andere deelnemers.

Naast Tsjechische en Slowaakse studenten werden nog 12 Nederlandse studenten van Universiteit van Amsterdam getest om data van Tsjechische en Slowaakse studenten met data van moedertaalsprekers te kunnen vergelijken. Alle Nederlanse studenten warenmoedertaalsprekers Nederlands met een afgeronde bacheloropleiding in de Nederlandse taalkunde.

\subsection{Materiaal}

De hypothesen en verwachtingen zijn met behulp van een uitgelokte productietaak getest. Het ging om dezelfde productietaak als die Ionin et al. (2008) hebben gebruikt. Deze taak werd door ons om praktische redenen korter gemaakt, uit het Engels naar het Nederlands vertaald en vervolgens door moedertaalsprekers Nederlands gecheckt. De uitgelokte productietaak in ons onderzoek bevatte 16 geëiste items en 12 fillers. De fillers werden gebruikt om het niet duidelijk te maken dat het onderzoek zich naar lidwoordgebruik richt.

De 16 geëiste items werden verdeeld in vier mogelijke combinaties van bepaaldheid en specificiteit ( $4 \times 4$ combinaties). De vier combinaties zijn in voorbeelden (2), (3), (4) en (7) weergegeven. Deelnemers konden bij elk geëist item uit het aanbod de / het / een / - kiezen. In tegenstelling tot de Russische deelnemers in Ionin et al. konden Tsjechische deelnemers dus het lidwoord ook weglaten.

De 12 fillers stelden dialogen voor waarin niet lidwoorden maar bijvoorbeeld een voorzetsel of een voornaamwoord werd geëist. Dit is geïllustreerd in (10).

(10) Filler item $o p$

Melle: Hoe gaat het met je nicht? 
Rachel: Het gaat heel goed met haar. Sterker nog, ze gaat deze zomer (op / naar / met/ -) reis naar Brazilië.

De deelnemers hebben 20 minuten de tijd gekregen om de hele taak uit te voeren.

\subsection{Procedure}

De deelnemers maakten de uitgelokte productietaak in november 2013 klassikaal. Alleen studenten die in 2013 hun opleiding afgerond hadden en studenten die op een buitenlands studieprogramma waren maakten de taak online.

\subsection{Analyse}

De testen zijn na het invullen door de onderzoekers nagekeken. Antwoorden met een geëist item werden als correct beschouwd. Ook als deelnemers een fout in het geslacht hadden gemaakt (het in plaats van de en andersom), werden deze antwoorden als correcteantwoord en gezien. Alle antwoorden met een niet-geëist ( $d e /$ het of - in plaats van een en een of - in plaats van de/het) of met een niet ingevuld item werden als fout beschouwd.

\section{Resultaten}

\subsection{Groepsresultaten}

Tabel (5) toont het succespercentage van moedertaalsprekers Nederlands en Tsjechische sprekers Nederlands in ons onderzoek en het succespercentage van Russische sprekers Engels uit het onderzoek van Ionin et al. uit 2008.

Tabel (5) Het succespercentage van Nederlandse en Tsjechische deelnemers uit ons onderzoek en van Russische deelnemers uit Ionin et al.'s onderzoek uit 2008

\begin{tabular}{|l|c|c|c|c|}
\hline & {$[+$ bep, + spec $]$} & [+bep, -spec] & [-bep, +spec] & [-bep, -spec] \\
\hline $\begin{array}{l}\text { moedertaalsprekers } \\
\text { Nederlands }\end{array}$ & 100 & 100 & 97,9 & 100 \\
\hline $\begin{array}{l}\text { moedertaalsprekers } \\
\text { Tsjechisch (n= 75) }\end{array}$ & 92 & 86,2 & 76,3 & 83,7 \\
\hline Brno (n=13) & 100 & 96,2 & 80,8 & 98,1 \\
\hline Olomouc (n=41) & 89,6 & 87,2 & 73,2 & 73,8 \\
\hline Praag (n=21) & 91,7 & 78,6 & 79,7 & 94,0 \\
\hline $\begin{array}{l}\text { moedertaalsprekers } \\
\text { Russisch (n=19) }\end{array}$ & 93 & 86 & 74,6 & 95,6 \\
\hline
\end{tabular}


Moedertaalsprekers maakten nauwelijks fouten, zoals verwacht was. De resultaten van Tsjechische sprekers Nederlands waren bijna hetzelfde als resultaten van Russische sprekers Engels in de [+bep, +spec], [+bep, -spec] and [-bep, + spec] condities, maar tot onze verbazing leverden ze geen goede prestatie in [-bep, -spec], zoals dat wel verwacht was. Aangezien moedertaalsprekers in deze conditie $100 \%$ correct waren, kon er geen sprake van een foutief item zijn. Maar als we naar het succespercentage van alle universiteiten kijken, is het duidelijk dat alleen studenten uit Olomouc in deze conditie zwak presteerden $(73,8 \%)$. Studenten uit Brno en Praag scoorden in deze conditie goed. Een nadere analyse van de resultaten laat zien dat alle deelnemers die in deze conditie maximaal $50 \%$ en minder scoorden, uit Olomouc kwamen (1 deelnemer met $0 \%$ succespercentage, 2 deelnemers met $25 \%$ succespercentage en 11 deelnemers met $50 \%$ succespercentage). Het feit dat de zwakste deelnemers van dit onderzoek uit Olomouc kwamen, legt het lage succespercentage van deelnemers uit Olomouc en bijgevolg het relatief zwakke succespercentage van alle deelnemers in deze conditie uit.

Tabel (6) toont in percentages de hoeveelheid correcte antwoorden en de soorten fouten in de vier condities van Tsjechische deelnemers, tabel (7) geeft die van de Russische deelnemers uit Ionin et al. (2008) weer. Het geëiste antwoord in elke conditie is vetgedrukt.

Tabel (6) Tsjechische resultaten, $\mathrm{n}=75$ (in \%)

\begin{tabular}{|l|c|c|}
\hline & $\begin{array}{c}\text { [+bep]: de/het } \\
\text { geëist }\end{array}$ & [-bep]: een geëist \\
\hline$[+\mathrm{spec}]$ & $\mathbf{9 2 , 0}$ de/het & 21,0 de/het \\
& 5,3 een & $\mathbf{7 6 , 3}$ een \\
& $2,7---$ & $1,7---$ \\
& 0 niet ingevuld & 1,0 niet ingevuld \\
\hline$[-\mathrm{spec}]$ & $\mathbf{8 6 , 2}$ de/het & 11,0 de/het \\
& 6,3 een & $\mathbf{8 3 , 7}$ een \\
& 7 --- & 5,3 --- \\
& 0,5 niet ingevuld & 0 niet ingevuld \\
\hline
\end{tabular}

Tabel (7) Russische resultaten, $\mathrm{n}=19$ (Ionin et al., 2008) (in \%)

\begin{tabular}{|l|l|l|}
\hline & {$[+$ bep]: the geëist } & {$[-$ bep $]: ~ a$ geëist } \\
\hline \multirow{5}{*}[+\text{spec}]{} & $\mathbf{9 3 , 0}$ the & 23,7 the \\
& 5,3 a, an & $\mathbf{7 4 , 6}$ a, an \\
& $0---$ & $0--$ \\
& 0,9 iets anders & 1,8 iets anders \\
\hline \multirow{5}{*}[-\text{spec}]{} & $\mathbf{8 6 , 0}$ the & 3,5 the \\
& 14,0 a, an & $\mathbf{9 5 , 6}$ a, an \\
& $0---$ & $0---$ \\
& 0 iets anders & 0,9 iets anders \\
\hline
\end{tabular}


Tabellen (6) en (7) laten zien dat het overmatige gebruik van een door Tsjechen in de [+bep, + spec] conditie en het overmatige gebruik van de/het in [-bep, + spec] bijna hetzelfde is als het overmatige gebruik van een en de/het door Russen. In [+bep, -spec] hebben Tsjechen een slechts in 6,3\% van de gevallen overmatig gebruikt en dat is veel minder dan het overmatige gebruik van een in dezelfde conditie door Russen $(14,0 \%)$. In deze conditie hebben ze het lidwoord vaak weggelaten $(7 \%)$. Een nadere analyse laat zien dat Tsjechische deelnemers bij een item in het bijzonder het lidwoord vaak hebben weggelaten (in 14,7\%). Dit item is geillustreerd in (11).

\section{(11) Geëiste item: het}

Marcus: Kom je met je vriend Peter bij mij op bezoek dit weekend? Loek: Ik kom wel, maar Peter niet. Hij is naar (de / het / een/-) huis van zijn oom George gegaan... Ik weet helemaal niet waar het is. Maar hij was er heel enthousiast over!

Verondersteld wordt dat deelnemers aan dit onderzoek het lidwoord in dit item weglieten omdat ze dachten dat het om een vaste uitdrukking "naar huis gaan" ging, waar geen lidwoord vereist is. Een soortgelijk effect van dit item kwam naar voren in het onderzoek van Ionin et al. (2008), waar Spaanse sprekers in een Engelse zin dezelfde fout maakten. Zowel in het Nederlands als in het Spaans bestaat deze vaste uitdrukking waar het lidwoord weggelaten is. Daarom is er niet alleen in Ionin et al. (2008) maar ook in ons onderzoek sprake van een item effect. Niettemin kan worden verondersteld dat wanneer Tsjechen het lidwoord niet zouden hebben weggelaten, zouden ze het lidwoord een in de meeste gevallen in de conditie [+bep, -spec] gebruiken. In de laatste conditie, [-bep, -spec], gebruikten Tsjechen het bepaalde lidwoord de/het veel vaker dan Russen (11\% tegenover $3,5 \%$ ). Een gedetailleerde analyse toont aan dat dit door deelnemers uit Olomouc werd veroorzaakt. Waar deelnemers van de andere twee universiteiten de/het in deze conditie helemaal niet (Brno - 0\%) of bijna niet (Praag - 3,6\%) gebruikten, gebruikten studenten uit Olomouc het bepaalde lidwoord in deze conditie vaak $(17,2 \%)$. Dit veelvuldige gebruik van het bepaalde lidwoord in deze conditie door een bepaalde deelgroep heeft het relatief frequente gebruik van de/het in de [-bep, -spec] conditie van de Tsjechische deelnemers veroorzaakt.

\subsection{Schommeling en taalvaardigheidsniveau}

Naast de hypothese dat Tsjechische sprekers Nederlands tussen bepaaldheid en specificiteit in het Nederlandse lidwoordgebruik zouden schommelen was de hypothese dat de schommeling tussen bepaaldheid en specificiteit in het Nederlandse lidwoordgebruik zou dalen naarmate het taalvaardigheidsniveau van Tsjechische 
sprekers Nederlands verbeterde. Om deze hypothese te kunnen bevestigen, zouden sprekers met een hoger taalvaardigheidsniveau minder fouten in [+bep, -spec] en [-bep, +spec] moeten maken dan sprekers met een lager taalvaardigheidsniveau. De onderstaande tabel (8) geeft het succespercentage van alle taalvaardigheidsgroepen in alle vier de condities.

Tabel (8) Het succespercentage per conditie en taalvaardigheidsniveau

\begin{tabular}{|l|c|c|c|c|}
\hline & [+bep, +spec] & [+bep, -spec] & [-bep, +spec] & [-bep, -spec] \\
\hline geëist & de/het & de/het & een & een \\
\hline A2 (n= 20) & 88,8 & 77,5 & 62,5 & 73,8 \\
\hline B1 (n= 21) & 91,7 & 90,5 & 73,8 & 81 \\
\hline B2 (n= 22) & 90,9 & 87,5 & 83 & 87,5 \\
\hline C1 (n= 12) & 100 & 91,7 & 91,7 & 97,9 \\
\hline
\end{tabular}

De data in tabel (8) laten zien dat afzonderlijke taalvaardigheidsgroepen verschillend presteerden. In alle vier de condities werden minder fouten gemaakt naarmate de taalvaardigheid hoger werd. In de [+bep, -spec] en [-bep, + spec] condities was deze verbetering markant (respectievelijk van 77,5\% naar 91,7\% en van $62,5 \%$ naar $91,7 \%$ ). Hoewel taalvaardigheidsgroep B1 in de [+bep, -spec] conditie beter presteerde dan de B2 groep, was dit verschil minimaal (3\%). In andere gevallen gold dat minder gevorderde sprekers meer fouten maken dan meer gevorderde sprekers. In $[+b e p,+$ spec] conditie presteerden B1 sprekers ook beter dan B2 sprekers maar dit verschil was ook minimaal $(0,8 \%)$. De hypothese werd dus bevestigd.

De data in de onderstaande tabel (9) ondersteunen de hypothese ook. In de tabel is het overmatige gebruik van het onbepaalde lidwoord een in de [+bep, -spec] conditie en het bepaalde lidwoord de/het in de [-bep, +spec] conditie weergegeven.

Tabel (9) Het overmatige gebruik van lidwoorden (in \%)

\begin{tabular}{|l|l|l|}
\hline & [+bep, -spec] & [-bep, +spec] \\
\hline overmatig gebruik van: & een & de/het \\
\hline A2 (n= 20) & 11,3 & 32,5 \\
\hline B1 ( $=\mathbf{2 1})$ & 1,2 & 25 \\
\hline B2 ( $=\mathbf{2 2})$ & 6,8 & 13,6 \\
\hline C1 $(\mathbf{n}=\mathbf{1 2})$ & 6,3 & 8,3 \\
\hline
\end{tabular}


In beide condities daalt het overmatig gebruik van een verkeerd lidwoord gaandeweg. Alleen in de [+bep, -spec] conditie presteert de taalvaardigheidsgroep B1 opnieuw beter dan de B2 groep (verschil 5,6\%).

\section{Discussie}

Dit onderzoek stelde zich tot doel twee hypothesen te toetsen betreffende het gebruik van bepaalde en onbepaalde lidwoorden door Tsjechische studenten Nederlands. De eerste hypothese stelde dat Tsjechische sprekers tussen bepaaldheid en specificiteit zouden schommelen. Aangezien de deelnemers van dit onderzoek een in de [+bep, -spec] conditie en de/het in [-bep, +spec] overmatig gebruikten, werd de eerste hypothese bevestigd.

De tweede hypothese was dat de schommeling tussen bepaaldheid en specificiteit in het Nederlandse lidwoordgebruik zou dalen naarmate het taalvaardigheidsniveau van Tsjechische sprekers Nederlands hoger wordt. Hoewel de resultaten aantonen dat een van de taalvaardigheidsgroepen afwijkt, B1-sprekers scoren namelijk in twee condities beter dan B2-sprekers, is duidelijk te zien dat sprekers van een lager taalvaardigheidsniveau meer fouten maken in de [+bep, -spec] en [-bep, + spec] condities dan sprekers van een hoger taalvaardigheidsniveau. Zodoende is dus ook de tweede hypothese bevestigd.

De analyse van de resultaten heeft getoond dat de deelnemers uit Olomouc op één conditie na in alle condities het slechts hebben gepresteerd. Dit is waarschijnlijk veroorzaakt door het feit dat deze groep de meeste deelnemers met lage taalvaardigheidsniveaus A2 en B1 bevatte (20 deelnemers in Olomouc, 10 in Brno en 11 in Praag). De zwakke sprekers in de groep uit Olomouc hebben het succespercentage van de gehele groep negatief beïnvloed. Het is ook mogelijk dat studenten uit Olomouc vrij zwak hebben gepresteerd omdat ze in de eerste twee studiejaren, wanneer hun taalvaardigheid nog vrij laag is, een audio-linguale studiemethode gebruiken. Deze methode focust zich namelijk niet op de grammaticale correctheid in de taalverwerving en dat kan het succespercentage van deze studenten in dit onderzoek negatief hebben beïnvloed.

Helaas is er geen verklaring voor waarom B1 sprekers in twee condities, in [+bep, + spec] en [+bep, -spec], beter hebben gepresteerd dan de gevorderde groep B2. Aangezien B1 in de andere twee condities beter dan de A2 groep, maar slechter dan de B2 groep heeft gepresteerd, kan niet beweerd worden dat de B1 groep gewoon beter in de grammatica is dan de andere taalvaardigheidsgroepen. Het is echter mogelijk dat de afwijking van de B1 groep door een verkeerde vaststelling van het taalvaardigheidsniveau is veroorzaakt. In dit onderzoek is het taalvaardigheidsniveau vastgesteld aan de hand van een behaald $\mathrm{CNaVT}$ certificaat. Omdat dit certificaat maar een keer per jaar gehaald kan worden, drukt het niet het actuele taalvaardigheidsniveau van de deelnemers uit. Voor een toekomstig 
onderzoek bevelen wij daarom an het taalvaardigheidsniveau van deelnemers met behulp van een andere toets kort voor het echte onderzoek vast te stellen.

\section{Conclusie}

Dit onderzoek heeft zich gericht op het lidwoordgebruik in het Nederlands door Tsjechische studenten Nederlands aan drie verschillende Tsjechische universiteiten. Door de methode van onderzoek van Ionin et al. (2008) te gebruiken is gebleken dat Tsjechische studenten Nederlands, net als Ionin's Russische leerders Engels, in hun lidwoordgebruik tussen bepaaldheid en specificiteit schommelen omdat ze een in de [+bep, -spec] conditie en de/het in de [-bep, +spec] conditie overmatig gebruiken. De analyse van de resultaten van afzonderlijke taalvaardigheidsgroepen heeft laten zien dat de schommeling tussen bepaaldheid en specificiteit afneemt naarmate het taalvaardigheidsniveau hoger wordt.

Dit onderzoek heeft laten zien dat de verwerving van Nederlandse lidwoorden niet alleen met het grammaticaal geslacht maar dat ook het verschil tussen het gebruik van bepaalde en onbepaalde lidwoorden problematisch is. De onderzoeksresultaten hebben bevestigd dat Tsjechische studenten Nederlands in twee condities de meeste fouten maken. Ze kiezen namelijk vaak een verkeerd lidwoord voor zelfstandige naamwoorden die bepaald en tegelijkertijd non-specifiek zijn en voor zelfstandige naamwoorden die onbepaald en tegelijkertijd specifiek zijn. Deze twee condities verdienen daarom extra aandacht tijdens het leren van het Nederlands. Dit zou idealiter in leerboeken Nederlands voor studenten met een Slavische achtergrond weerspiegeld moeten worden.

\section{Bibliografie}

Ionin, Tania (2003): Article Semantics in Second Language Acquisition. Massachusetts: Massachusetts Institute of Technology.

Ionin, Tania e.a. (2004): “Article semantics in L2-acquisition: the role of specificity.” In: Language Acquisition. 12, 3-69.

Ionin, Tania e.a. (2008): "Sources of linguistic knowledge in the second language acquisition of English articles." In: Lingua 118:554-576.

Schaeffer Jeannette/ Lisa Matthewson (2005): "Grammar and Pragmatics in the Acquisition of Article Systems.” In: Natural Language and Linguistic Theory 23, 52-101.

Neerlandica Wratislaviensia 26, 2016

(C) for this edition by CNS 